\title{
NEW EVIDENCE ON CLASSROOM COMPUTERS AND PUPIL LEARNING
}

\author{
Joshua Angrist \\ Victor Lavy
}

Working Paper 7424

http://www.nber.org/papers/w7424

\author{
NATIONAL BUREAU OF ECONOMIC RESEARCH \\ 1050 Massachusetts Avenue \\ Cambridge, MA 02138 \\ November 1999
}

We thank Analia Schlosser and David Matsa for outstanding research assistance, and the staff in the Chief Scientist's Office, the Evaluation Division, and the Information Systems Division of the Israeli Ministry of Education for help with data. Thanks also go to Jeff Kling, Alan Krueger, and seminar participants at Berkeley and the MIT Labor Lunch for helpful comments. The views expressed herein are those of the authors and not necessarily those of the National Bureau of Economic Research.

(C) 1999 by Joshua Angrist and Victor Lavy. All rights reserved. Short sections of text, not to exceed two paragraphs, may be quoted without explicit permission provided that full credit, including $\mathbb{C}$ notice, is given to the source. 
New Evidence on Classroom Computers and Pupil Learning Joshua Angrist and Victor Lavy

NBER Working Paper No. 7424

November 1999

JEL No. H41, I28, J24

\begin{abstract}
The question of how technology affects learning has been at the center of recent debates over educational inputs. In 1994, the Israeli State Lottery sponsored the installation of computers in many elementary and middle schools. This program provides an opportunity to estimate the impact of computerization on both the instructional use of computers and on pupils' test scores. Results from a survey of Israeli school-teachers show that the influx of new computers increased teachers' use of computer-aided instruction (CAI) in the $4^{\text {th }}$ grade, with a smaller effect on CAI in $8^{\text {th }}$ grade. CAI does not appear to have had educational benefits that translated into higher test scores. Results for $4^{\text {th }}$ graders show sharply lower Math scores in the group that was awarded computers, with smaller (insignificant) negative effects on verbal scores. Results for $8^{\text {th }}$ graders' test scores are very imprecise, probably reflecting the much weaker first-stage relationship between program funding and the use of CAI in $8^{\text {th }}$ grade. The estimates for $8^{\text {th }}$ grade Math scores are also negative, however.
\end{abstract}

Joshua Angrist

Department of Economics

MIT E52-353

50 Memorial Drive

Cambridge, MA 02139-437

and NBER

angrist@mit.edu

\author{
Victor Lavy \\ Department of Economics \\ Hebrew University \\ Mt. Scopus \\ Jerusalem 91905 \\ ISRAEL \\ msvictor@mscc.huji.ac.il
}




\begin{abstract}
"That small miracle can be replicated in every school, rich and poor, across America ... Every child in American deserves a chance to participate in the information revolution." President Clinton, at the East Somerville Community School, June 5, 1998.

"We could do so much to make education available 24 hours a day, seven days a week, that people could literally have a whole different attitude toward learning." Newt Gingrich talking to the Republican National Committee (quoted in Oppenheimer, 1997).

"Netanyahu explained to a group of politicians and computer professionals how he wanted to provide a quarter-million of his country's toddlers with interconnected computers." Recounted by MIT computer scientist Michael Dertouzos, September 1998.
\end{abstract}

Politicians, educators, parents, and researchers have long looked to technology to improve schools. One of the earliest advocates for technology in the classroom was Thomas Edison, who predicted in 1922 that motion pictures would revolutionize education and "be an epoch in the common school" (Israel, 1998). Edison himself funded educational films, though he also complained about lack of teacher interest and high production costs. In the 1950s Psychologist B.F. Skinner published a series of papers predicting that “teaching machines" would make learning dramatically more efficient (see, e.g., Skinner, 1954, 1958). Skinner's writing reflects a modern-sounding emphasis on "the constant interchange between program and student" and the value of "home instruction." Recent years have seen renewed and even more intense interest in classroom computer use, including interest in the use of computers in schools in less-developed countries (see, e.g., Anandakirichnan, 1988).

The educational use of computers generally falls under two broad headings. The first is computer skills training (CST), which teaches students about computers. The second is computer-aided instruction (CAI), which "uses computers to teach things that may or may not have any relation to technology" (President's Committee of Advisors on Science and Technology, 1997). CST is essentially vocational, and includes things like keyboarding skills, instruction in the use of word processing, database management, the use of spreadsheets and other software tools, and the study of computer programming.

Basic familiarity with CST skills seems undeniably useful, just as typing was a useful skill taught 
in American high schools earlier in the century. But most of the recent interest in the educational use of computers focuses on CAI and not CST. This focus is reflected in the report of the President's Committee of Advisors on Science and Technology Panel on Education Technology, in Apple Computer's "Classrooms of Tomorrow" project (Baker, Gearhart, and Herman, 1993), and in the growing interest in "distance learning" in schools and universities. In contrast with the apparent consensus regarding the value of at least some level of computer literacy, the role of CAI remains controversial. Skinner's claims notwithstanding, the theoretical case for CAI is not well-developed, and there are good reasons to believe that computers can actually be a diversion. One widely-cited proponent of this negative view is Stoll (1995), who compared computers to the children's television program Sesame Street, arguing that (p. 147) "Both give you the sensation that merely by watching a screen, you can acquire information without work and discipline."

The question of CAI effectiveness is of much more than academic interest since CAI infrastructure is expensive and may take resources from other educational uses. ${ }^{2}$ Perhaps the most important shortcoming in the case for further investment in CAI infrastructure is the fact that the evidence for effectiveness is both limited and mixed. Although CAI has been around for decades, there are few empirical studies that meet a rigorous methodological standard. Many studies are qualitative, gathering impressions from participants in demonstration projects, or quantitative but with no real comparison group. The results of those studies that do attempt to compare outcomes between CAI-trained pupils and other pupils are hard to assess. A recent review by Kirkpatrick and Cuban (1998) catalogs both individual studies and meta-analyses that find widelyranging effects. ${ }^{3}$

'Oppenheimer (1997) surveys Stoll's work and other critical assessments. See also Cuban
(1986).

${ }^{2}$ In 1998, Massachusetts schools bought 40,000 computers, and the State Department of Education urges schools to replace one-quarter of them annually (Seltz, 1999).

${ }^{3}$ Economists have looked at $\mathrm{CAI}$ in their own discipline. An early reference on $\mathrm{CAI}$ in economics teaching is Booms and Kaltreider (1974). Porter and Riley (1992) argue that CAI has not been shown to be effective in economics. A recent study by Wenglinsky (1998) using nationally 
In this paper, we provide new evidence on the educational consequences of CAI. Our study exploits an episode in Israel that facilitates controlled comparisons. In 1994, the Isracli State lottery, which uses lottery profits to sponsor various social programs, funded a large-scale computerization effort in many elementary and middle schools. By June 1996, about 10 percent of the country's elementary school pupils and about 45 percent of the country's middle schools pupils had received new computers as a consequence. ${ }^{4}$ This episode is used here to estimate the effect of the new technology on both teachers' use of CAI and their pupil test scores.

A variety of unique data sources facilitate our analysis of computers in schools, and allow us to estimate the effects of CAI effects using a number of statistical methods. In addition to OLS estimates of the effect of CAI, we use a dummy for program receipt as an instrument for CAI intensity, and we develop a non-linear instrumental variables estimator that exploits information about applicants' priority ranking for program funding as determined by local authorities. These methods consistently show that the influx of new computers in 1994 and 1995 led to a substantial increase in the use of CAI, especially in elementary schools. There is no evidence, however, that increased educational use of computers actually raised pupil test scores. In fact, the results show a statistically significant decline in the test scores in fourth grade Math classes, where the new computers had the largest impact on instructional techniques.

representative samples finds both positive and negative effects. For other examples and surveys, see, e.g., Knight, et al (1981), Kulik and Kulik (1991), Liao (1992), and Cuban (1986, 1993). A literature started by Krueger (1993) looks at the effect of computer-use on wages, but this is probably best-viewed as the impact of CST and not CAI. Levy and Murnane (1996) discuss the consequences of employer-
provided CST.

${ }^{4} \mathrm{Much}$ of the software used in the program is from the Center for Educational Technology (CET), a private company that accounts for most of the educational software market in Israel. The CET sells educational software in the US and Europe though a number of well-known foreign partners. 


\section{Data and background}

A. The Tomorrow-98 program

As in the US, many Israeli schools have long had some sort of computer equipment for instructional use, but the Tomorrow-98 program (in Hebrew, "Mahar") allowed for a significant upgrade. The main focus of this program was on the "computerization of the education system", accomplished by ". . creating a supportive environment that can integrate information technologies in a range of activities within the school," "training teachers to integrate computers in teaching," and "equipping schools with hardware and software, and replacing outdated incompatible equipment" (Israel Ministry of Education, Culture and Sport, 1994, p. 36). The program included significant funding for teacher training as well as hardware and software. Between 1994 and 1996, the first three years of the program, 35,000 computers were installed in 905 schools. In 1994, 474 schools received computers and training. In 1995, schools received 16,000 computers through the program. In 1996, more computers were installed and 2,100 primary-school Math teachers received training in CAI (Israel Ministry of Education, Culture, and Sport, 1996). The target student-computer ratio was $10: 1$, to be achieved by 1998 , the fifth and final year of the program. Most of the funding came from the Israeli State Lottery, with additional money from the Ministry of Education and local authorities.

Funds for Tomorrow-98 were distributed through an application process. Individual towns and regional authorizes applied for funds by submitting a list of elementary and middle schools to be computerized, ranked according to the municipalities' assessment of the schools ability to make good use of the computers. This generally meant the schools had some sort of pre-existing computer infrastructure and some "need" and "ability" to make use of the computers. The Ministry of Education used a set of guidelines to distribute the project money to schools in towns that applied. Priority was given to towns with a high proportion of 7 th and 8 th grade enrollment in stand-alone middle schools (as opposed to combined 1-8 schools). After high-priority municipalities received an allocation for their middle schools in a 1:10 computer:pupil ratio, equipment was distributed down the municipalities priority list. In this process, each 
town received money to computerize their elementary and $1-8$ schools in a 1:10 ratio up to a ceiling. The ceiling was determined by the municipal grade 1-8 enrollment as a proportion of national grade 1-8 enrollment. The first computers funded by Tomorrow were delivered in September, 1994.

\section{B. Data}

The main data source for this study is a test given to pupils attending a random sample of elementary and middle schools in June 1996. Schools from different sectors (Arab/Jewish) and types (religious/secular) were sampled, but we look only at Jewish schools (including religious and secular schools). The total number of Jewish schools sampled was about 200, but only 122 of these applied for Tomorrow-98 program money. The test was designed and conducted by the National Institute for Testing and Evaluation (NITE), which runs college admissions testing in Israel.

Test score data were collected as follows: in each sampled school with a fourth grade (i.e., an elementary school or a 1-8 school), one class was chosen to take a test in Math and one class was chosen to take a test in Hebrew. Similarly, in schools with an eighth grade, one class was chosen to be tested in Math and one class was chosen to be tested in Hebrew. Schools having both fourth and eight grades (i.e., 1-8 schools) contribute test scores for both grades. If there were more than two classes in a grade, two classes were chosen for testing at random. The pupil data consists of individual records with either a Math or Hebrew score, and pupil demographic data from school records. The demographic data include age, sex, immigrant status, and special-education status. The tests are grade-normed achievement tests, with scores measured as percent-right.

The NITE data on test scores is combined with data from a brief survey (also designed by NITE) given to all the teachers of each sampled class. The teachers survey and pupil testing was done at the same time. Because each fourth or eighth grade class is potentially taught by a number of teachers for a range of subjects (i.e., Math, Hebrew, Science, Bible), we attempted to identify the principle Math and Hebrew 
teacher for each class. Our analysis file uses data on these teachers only; that is, our analysis of Math scores includes information for a teacher we identified as the principle Math teacher of the class.

The teachers' survey collected information about how teachers teach, including their use of technology in the classroom, and their views on a variety of issues related to technology, teacher training, and instructional methods. Data on CAI were collected in the following question:

Which of the following do you use when teaching?

a. xeroxed worksheets

b. instructional booklets

c. games

d. computer software or instructional computer programs

e. TV programs

f. Other audio-visual materials

Teachers responded to each item using a 4-point intensity scale:

not at all $(0)$

sometimes (1)

frequently (2)

almost always (3)

The response to item (d) is our measure of CAI. In addition to these survey responses, we asked the Ministry of Education to collect data on teacher demographic characteristics in a follow-up survey in Spring 1997.

The third component of our data base consists of information on Tomorrow implementation schedules and computer infrastructure in schools collected for the purposes of this evaluation. In 1998, the Ministry of Education obtained information from the contractors who installed the Tomorrow computers, with verification and additional information collected from school principals. This information includes the date of receipt of new equipment from Tomorrow, the extent and type of pre-1994 computer resources, and information about non-program computers received between 1994 and 1996. Pre-existing computers are described as either "sophisticated" (IBM XT or better), or "non-sophisticated"(Commodore-type machines). Schools may have had no computers, non-sophisticated machines, or both types.

The fourth component of our data base contains information about schools in 1996 and 1991. The 
1996 data come from Ministry of Education files, and includes things like the Israeli Pupil Disadvantaged (PD) index and school size. The PD index is an important summary statistic used to categorize schools and to make school funding decisions in Israel. The 1991 school-level data comes from the data set used in the Angrist and Lavy (1999) study of class size. This data set provides information on lagged test scores. In the analysis of fourth grade scores, we use the 1991 school average Math and Hebrew scores in fourth grade to control for possible differences in performance across schools. In the analysis of eighth grade scores, we use a less direct control for lagged scores since we have no early information on eighth grade scores. For 1-8 schools, the eighth grade lagged scores are those of 4 th and 5 th graders in these same schools in 1991. For each 7-9 school, the lagged scores are the averages of the 1991 4th and 5th grade scores from the clementary schools that feed that school. A data appendix describes the procedures used to match the various data sources in greater detail.

\section{Descriptive statistics and OLS estimates}

\section{A. Descriptive statistics}

Descriptive statistics are reported in Table 1 for three samples, separately for each combination of grade and subject. The first sample for fourth grade Math scores consists of 4,779 pupils in 181 schools. This is the full sample of Jewish fourth graders for whom we have 1996 Math scores. The second sample is limited to pupils in schools that applied for Tomorrow funds, and includes 3271 pupils in 122 schools. The third sample is the subset of the applicant sample for which we were able to obtain 1991 score data. This includes 2891 pupils in 107 schools. The three samples for other grades and subjects are organized similarly.

The average fourth grade test score ranges from 67-69 with a standard deviation of around 20. The average eighth grade test score ranges from 57-66, also with a standard deviation around 20. There is little evidence of differences in test scores across subsamples in any grade/subject category. Other variables 
described in the table include an indicator for any use of CAI, and the computer-use intensity ranking, with a mean of around .8 for fourth graders and .4 for eight graders. This ranking is the main regressor of interest. The next line in the table shows the mean proportion of applicants that received Tomorrow program funding. This proportion is .14-.17 for fourth graders and around .5 for eighth graders. The difference by grades reflects the higher priority given to program funding for middle schools. Descriptive statistics for control variables and lagged test scores are also shown in the table. The pupil disadvantage (PD) index is measured on a standardized scale.

In addition to being more likely to get program funding, eighth graders also had the use of program computers for longer: an average of 13 months versus about 9 months for fourth graders. Still, on average, fourth graders had the use of computers for a full school year as of the test date in 1996. It is also noteworthy that almost half of fourth grade and almost two-thirds of eighth grade pupils had access to some sort of computer technology before the Tomorrow program.

Pupils in schools that use computers for instruction differ in a variety of ways from those that have little or no usage. This can be seen in Table 2, which reports variable means by computer-use intensity and Tomorrow program status. ${ }^{5}$ For both grades, pupils in schools with more intense use of CAI tend to be from somewhat more disadvantaged backgrounds, though these differences are not all significant. This may reflect a general tendency in the Israeli school system to direct resources and programs to schools on a remedial basis (Lavy, 1995). Among fourth graders, heavier computer users are also more likely to have had some (relatively) sophisticated computer equipment before 1994. Eighth graders tested in Math were less likely to have had sophisticated computers but more likely to have had unsophisticated computers. There is no

\footnotetext{
${ }^{5}$ The standard errors for differences in means in Table 2 and the regression estimates in Tables $3-$ 6 are corrected for school-level clustering using equation (1) in Moulton (1986). Intra-class correlation coefficients for test-score regression residuals are on the order of .12 for OLS and reduced-form estimates, with somewhat higher coefficients for 2 SLS. other variables that vary only at the school level have intraclass correlation coefficients of 1 .
} 
relationship between the presence of previous computer equipment and computer use for eighth graders tested in Hebrew. This may be because eighth-grade schools were already relatively well-equiped, though it should also be noted that the "previous computers" measures are retrospective reports by principals that may not be very accurate. Lagged test score differences by CAI status are not significant.

More important for our purposes than differences by computer-usage are differences by Tomorrow98 program status. Fourth grade program participants are more likely to be disadvantaged (a significant difference only for schools tested in Hebrew), but this is reversed for eighth graders. These relationships are broadly consistent with features of the selection process for Tomorrow-98 funding that were described to us. Among eighth graders, middle schools received priority over 1-8 schools; in Israel these schools tend to be located in better areas. Among fourth graders, some preference was given to schools with a higher proportion of disadvantaged students. In any case, it is clear that control for pupil background and school type may be important when attempting to estimate the effect of the program. Another noteworthy difference is an increased likelihood of having pre-program access to relatively sophisticated computers among program participants, both in $4^{\text {th }}$ and $8^{\text {th }}$ grade.

Among fourth graders, there is little clear evidence of a difference in 1991 test scores by Tomorrow98 program status, while for eighth graders the differences are positive and somewhat larger. Except for the verbal scores of eighth graders tested in math, however, non of the contrasts in lagged scores by program status is significant. This is important since increasing similarity between program and non-program groups increases the likelihood that post-treatment differences in test scores are actually caused by the program.

\section{B. Computers and test scores}

The estimation framework is based on the following causal model. For the $i$ th student in school $s$, we assume that potential test scores for alternative levels of CAI are given by:

$$
\mathrm{y}_{\mathrm{is}}=\mathrm{W}_{\mathrm{s}}^{\prime} \gamma+\mathrm{X}_{\mathrm{i}}^{\prime} \beta+\mathrm{c}_{\mathrm{is}} \alpha+\eta_{\mathrm{s}}+\epsilon_{\mathrm{is}}
$$


where $y_{i s}$ is the test score for pupil $\mathrm{i}$ in school s, $\mathrm{W}_{\mathrm{s}}$ is a vector of school characteristics, $\mathrm{X}_{\mathrm{i}}$ is a vector of pupil characteristics, and $\mathrm{c}_{\mathrm{is}}$ is the computer-use intensity ranking coded from pupil i's teacher's response to the teacher survey. Since all pupils tested in the same subject and grade have the same teacher, in practice $\mathrm{c}_{\mathrm{is}}$ varies only with $\mathrm{s}$. The other school characteristics, $\mathrm{W}_{\mathrm{s}}$, include things like the proportion of disadvantaged pupils in the school. The pupil characteristics, $X_{i}$, include things like immigrant status. The error term $\eta_{s}$ is an i.i.d. random school effect that is introduced to parameterize within-school correlation in scores. The remaining error component, $\epsilon_{\mathrm{is}}$, is specific to pupils. The coefficient, $\alpha$, is the parameter of primary interest.

Fourth graders in schools where teachers report using more CAI generally have higher Math scores, but there is little evidence of an association between CAI and Hebrew scores in either grade. This can be seen in Table 3, which reports OLS estimates of the relationship between CAI intensity and test scores for applicants, for applicants with test score data, and for a sample of pupils in large towns. This last sample is used to control for town fixed effects, and includes any pupil (whether or not their school applied for Tomorrow funds) living in a town with at least two schools.' The positive effects for fourth-grade Math scores are only marginally larger than their standard errors in the applicants' samples. Moreover, control for town effects reduces the program effects for fourth graders essentially to zero.

OLS results for eighth graders in the two applicant samples show no evidence of a relationship between CAI intensity and test scores in either subject. In the town-effects sample for eighth grade Math scores, however, there is a marginally significant negative score effect of -2.8. Except for the Hebrew scores of fourth graders, Table 3 shows a pattern of declining effects as the models included larger sets of schools,

'All the estimates for fourth graders control for sex, immigrant status, special education status, school enrollment, the pupil disadvantage index, and whether schools had simple or sophisticated computers before 1994. Estimates for eighth grade Hebrew scores include these controls plus dummies for school type. Estimates for eighth grade Math scores omit controls for immigrant and special education status. 
i.e., progressing from a specification for applicants, to applicants with lagged test scores, to control for town effects. This suggests that part of the positive association in column 1 is due to omitted variables that are positively associated with scores and computer use.

III. Instrumental-variables estimates

A. Reduced-form program effects

Fourth-grade pupils in schools that received funding from the Tomorrow program were much more likely to be exposed to CAI when studying both Math and Hebrew than pupils in schools that did not receive funding. Of course, this may reflect pre-program differences, but controls for the presence of computers in the school before the program should mitigate pre-program differences. In contrast with the results for fourth graders, program funding had relatively little effect on eighth grade teaching methods in either subject. These relationships can be seen in columns 1-2 and 5-6 of Table 4, which reports reduced-form effects of the Tomorrow program on CAI usage and test scores. The difference in program impact on CAI across grades is consistent with the fact that CAI is generally used less widely in upper grades.

For fourth graders, there is a clear and at least marginally significant negative relationship between Tomorrow program status and test scores, with pupils in the Tomorrow group scoring 3.5-5 points lower than other pupils. Fourth-grade Hebrew scores and eighth-grade Math scores are also lower in the program group, though these differences are not significant. Eighth-grade Hebrew scores are slightly higher for program participants, though here too the difference is not significant. Overall, however, while there is clear evidence that computers funded by Tomorrow-98 led to an increase in CAI, there is no evidence that this translated into higher test scores. The only statistically significant test score difference is the negative effect on fourth grade Math scores, and two out of three of the other groups show negative effects. ${ }^{2}$

${ }^{2}$ Similar results are obtained when the dummy for Tomorrow-98 is replaced with a variable measuring the number of months Tomorrow-98 computers were in schools. 


\section{B. 2SLS}

We use a dummy for receiving Tomorrow-98 computers $\left(\mathrm{T}_{\mathrm{s}}\right)$ as an instrument for the effect of CAI intensity $\left(\mathrm{c}_{\mathrm{is}}\right)$ on test scores. The resulting 2SLS estimates correspond to the OLS estimates reported in Table 3. Assuming the CAI intensity index fully reflects the avenues through which Tomorrow-98 funds affected test scores, the 2SLS estimates can be interpreted as estimating a weighted-average causal effect of increasing the intensity of CAI by one unit (see, e.g., Angrist and Imbens, 1995). The sign of the 2SLS estimates is necessarily the same as the sign of the reduced-form estimate in Table 4; the only change from the reduced form is a re-scaling. The first-stage equation for this procedure is

$$
\mathrm{c}_{\mathrm{is}}=\mathrm{W}_{\mathrm{s}}{ }^{\prime} \pi_{1}+\mathrm{X}_{\mathrm{i}} \pi_{2}+\mathrm{T}_{\mathrm{s}} \pi_{0}+\xi_{\mathrm{is}} \text {, }
$$

where $\pi_{0}$ is the first-stage effect. Estimates of $\pi_{0}$ in this equation were reported in columns 1-2 and 5-6 of Table 4 (the standard errors in that table allow for school-level clustering in $\xi_{\mathrm{is}}$ ).

The results of 2SLS estimation using all applicants and those with lagged test scores, reported in columns 1-2 and 6-7 of Table 5, suggest that increasing the intensity of CAI by one unit reduces the Math test scores of fourth graders by 7-9 points. Not surprisingly, given the reduced-form results, this is the only grade/subject category for which the 2SLS estimates are significant. ${ }^{3}$ The magnitude of the 2SLS estimate of the effect of CAI intensity on fourth grade Math scores is about $.4 \sigma$, where $\sigma$ is the sample standard deviation of test scores. The negative effects for fourth grade Hebrew scores are on the order of $.25 \sigma$, but this effect is roughly the size of the corresponding standard errors.

Table 5 also reports the results of three simple checks on the basic 2SLS specification. First, the estimates in columns 3 and 8 use samples composed entirely of pupils in schools that received Tomorrow-98 funding and for whom we have data on 1991 scores. As before, the instrument in this case is a dummy

${ }^{3}$ The t-statistics for 2SLS estimates are lower than the corresponding t-statistics for the reducedform effects because the 2SLS residuals are more highly correlated within schools than are the reducedform residuals. 
indicating whether the pupil is in a school that received funding before June 1996. But here the comparison group consists solely of pupils who received Tomorrow-98 computers after June 1996 (and before the end of December 1997, the last date we have information for). This strategy controls for the possibility that Tomorrow-98 winners differ in some unobserved way from Tomorrow-98 losers, thereby biasing 2SLS estimates of program effects. In fact, results using the "T-98/will-get-T-98" sample are remarkably similar to those in the full sample.

Second, columns 4 and 9 report the results of adding controls for the instructional $u$ se of computers (as opposed to possession of hardware) by fourth graders in 1991. This school-level variables provides an additional control for pre-existing differences between program winners and losers. The data on lagged computer use come from the same source as lagged test scores. Only a subset of schools have this information, which consists of the school average of indicators for whether teachers in the relevant grade in the school used computers for instruction. Control for lagged computer use has little effect on the estimates of the impact of computer use on fourth grade test scores.

Finally, columns 5 and 10 of Table 5 report the results of replacing a single T-98 dummy with up to 20 dummies indicating the month T-98 computers were used (the number of dummies depends on the subject and grade). If the instruments satisfy the exclusion restriction motivating 2 SLS estimation, this should lead to similar but more precise estimates than are generated by the basic specification. Results using months dummies as instruments are considerably more precise than estimates using a single dummy, though somewhat smaller than results from the basic specification. The differences in estimates across models is not statistically significant, however.

C. Non-linear instrumental variables

The 2SLS estimates discussed above may be biased if schools that received Tomorrow-98 computers differ in some way from those that didn't, even after controlling for observed covariates. Therefore, as a 
further check on the previous results, we explore an instrumental variables strategy related to the regressiondiscontinuity method used recently by Angrist and Lavy (1999) to estimate the effects of class size on test scores. This method exploits the fact that within towns, priority for Tomorrow- 98 funding was determined largely on the basis of the towns' priority ranking of applicant schools. Although there is no sharp discontinuity in the relationship between ranking and funding, we can use the fact that funding is a markedly nonlinear and non-monotonic function of rank to construct instruments for computer use while controlling for parametric nonlinear functions of rank.

For each school, s, let $r_{s}$ denote the school's rank on the list for the town where this school is located. That is, $r_{s}=1$ if the school is first on the priority list in the town, $r_{s}=2$ for the second school in the town, and so on, up to $\mathrm{N}_{\mathrm{s}}$, the number of schools on the list for the town. To adjust for the fact that the likelihood of being highly ranked may have varied with the number of applicants, we work with a normalized rank:

$$
\mathrm{R}_{\mathrm{s}}=\left(\left(\mathrm{N}_{\mathrm{s}}+1-\mathrm{r}_{\mathrm{s}}\right) / \mathrm{N}_{\mathrm{s}}\right)
$$

Note that not all schools were ranked, i.e., some schools were deemed ineligible for program funds by the towns. If schools were deemed ineligible for funding, we set $r_{s}=N_{s}+1$ so $R_{s}=0 .{ }^{4}$ Thus, $R_{s}$ ranges from 0 (ineligible for funds) to 1 (highest priority for funding). $\mathrm{R}_{\mathrm{s}}$ provides a potential instrumental variable that can be used to identify the effects of Tomorrow-98 computers or CAI on outcomes.

The estimation strategy implemented in Angrist and Lavy (1999) is based on the fact that the treatment is a known, nonlinear and discontinuous function of an underlying covariate. Identification comes from discontinuities or "jumps" that are known to exist in the assignment mechanism connecting the covariate and treatment at certain threshold values. Here, $\mathrm{R}_{\mathrm{s}}$ is a key covariate underlying treatment assignment, but the relationship between $\mathrm{R}_{\mathrm{s}}$ and assignment $\left(\mathrm{T}_{\mathrm{s}}\right.$, receipt of Tomorrow-98 funds) is not known

${ }^{4}$ We determine the number of applicants by counting them in Tomorrow-98 program data provided by the Ministry of Education. The town ranking of schools is also reported in this file. In some cases the maximum rank recorded in the data falls short of the apparent number of applicants, probably because schools were incorrectly grouped or identified. In such cases we set schools deemed ineligible for funding (i.e., ranked by the town at 0 ) to have $r_{s}=\max ($ rank recorded for the town $)+1$. 
a priori and there are no threshold values that generate discontinuities. In our setup, identification comes from the fact that, while continuous, $E\left[T_{s} \mid R_{s}\right]$ is still a richly nonlinear and non-monotonic function of $R_{s}$. We can therefore control for linear and even quadratic functions of $R_{s}$ while using $E\left[T_{s} \mid R_{s}\right]$ as an instrument for $\mathrm{c}_{\mathrm{is}}$.

Implementation of this approach requires an estimate of $E\left[T_{s} \mid R_{s}\right]$ since this is unknown. Following an idea developed by Hahn, Todd, and van der Klaauw (1999) for a related problem, we use local linear regression to estimate this conditional expectation function nonparametrically. Hahn, Todd, and van der Klauuw (1999) incorporate prior information on the location of discontinuities in their nonparametric estimates. Since there are no discontinuities in our case, we model $E\left[T_{s} \mid R_{s}\right]$ using the entire support of $R_{s}$. In particular, we use the Cleveland (1979) local linear regression smoother to construct fitted values, $\hat{\mathrm{E}}\left[\mathrm{T}_{\mathrm{s}} \mathrm{I}\right.$ $\mathrm{R}_{\mathrm{s}}$, for every value of $\mathrm{R}_{\mathrm{s}}{ }^{5}$ An important feature of our procedure is that we use the population of Tomorrow98 applicants to construct $\hat{E}\left[T_{s} \mid R_{s}\right]$. So our first-step estimation procedure generates a population fitted value and does not affect second-step (2SLS) standard errors when using $\hat{E}\left[T_{s} \mid R_{s}\right]$ as an instrument. Because there is uncertainly about bandwidth, however, we experimented with a number of choices.

The estimated $\hat{E}\left[T_{s} \mid R_{s}\right]$ is plotted in Figure 1 for elementary schools and Figure 2 for middle schools. These estimates are for the population of Tomorrow-98 applicants (the unit of observation is the school). Both figures show estimates for bandwidth choices of .2, .3, and .4. As the bandwidth gets wider, the estimated $\hat{E}\left[T_{s} \mid R_{s}\right]$ gets smoother. At the other extreme, very narrow bandwidths would interpolate every point. The points themselves, all zeros and ones since $T_{s}$ is binary, are also shown in the figure.

Figures 1 and 2 both show that schools with normalized rank below about .7 were much less likely to receive Tomorrow-98 computers than schools with higher rankings. For ranks of .7 and higher, the likelihood of receiving computers increases steeply with rank, though it flattens out below ranks of .9 for

${ }^{5}$ The Cleveland (1979) estimator is called LOWESS (see, e.g. Fan and Gijbels, 1995). We use the version of this estimator implemented in Stata. 
elementary schools. Interestingly, schools given a very low ranking by municipal authorities (i.e, below about .2) are more likely to have been given computers than schools with ranks between .2 and .6 . This is because Ministry of Education authorities sometimes over-rode low town rankings, apparently out of concern that towns' preferences over schools may be influenced by local political considerations.

Figures 3 and 4 show local linear regression estimates of the relationship between the normalized town ranking and test scores, parallel to those in Figures 1 and 2 (using a bandwidth of .4). The top half of Figure 3, for fourth grade Math scores, exhibits a pattern that is in some respects the mirror image of Figure 1. In particular, test scores begin to fall with rank for towns with ranks above about.7. Although there is some evidence of a decline for fourth grade verbal scores, the pattern less clear cut, consistent with the insignificant but negative estimates for verbal scores in Tables 4 and 5. For eighth graders, however, the only semblance of a pattern is slightly lower scores for low ranked schools and slightly higher scores for highly ranked schools. Both groups were more likely to receive Tomorrow-98 computers, so this pattern may be due to chance. Neither figure shows strong up or down "trend variation" in scores with rank.

The second stage estimation is based on a modified version of equation (1), where the term $W_{s}{ }^{\prime} \gamma$ is augmented by inclusion of $\mathrm{N}_{s}$ and linear and quadratic functions of $\mathrm{R}_{s}$ as regressors:

$$
y_{i s}=W_{s}^{\prime} \gamma+\delta_{0} N_{s}+\delta_{1} R_{s}+\delta_{2} R_{s}^{2}+X_{i}^{\prime} \beta+c_{i s} \alpha+\eta_{s}+\epsilon_{\text {is }}
$$

The quadratic function of $R_{s}$ controls for possible effects of the ranking that operate through mechanisms other than the likelihood of receiving new computers (although there is little evidence of such effects in the figures). The non-linear IV estimates were computed by 2SLS estimation of equation (3), using the estimated $\hat{E}\left[T_{s} \mid R_{s}\right]$ as an instrument for the endogenous regressor, $c_{i s}$.

The resulting estimates are broadly consistent with the basic 2SLS estimates reported in Table 5 . This can be seen in Table 6, which reports estimates for three bandwidth choices in the first-stage. As before, the clearest results are for fourth grade Math scores, with estimates ranging from about -3 to -13 . Some of these estimates are significantly different from zero. Estimates for fourth grade verbal scores and 
eighth grade math scores are also mostly negative, though none are significant. The estimates in columns 3 and 6 of the table are based on a sample limited to pupils in schools that had a normalized rank above .5 . These estimates involve a comparison that exploits variation in $\hat{E}\left[T_{s} \mid R_{s}\right]$ close to the level where the probability of receiving computers sharply increased. This limited sample may lead to better control for any omitted $\mathrm{R}_{\mathrm{s}}$ effects. In practice, the results in columns 3 and 6 are larger in magnitude and, with the exception of 8 th grade Math scores, less precise than the other results. ${ }^{6}$

\section{Conclusions}

Israel's Tomorrow-98 program provides a unique opportunity to assess the impact of computer technology in schools. The program had a clear impact on the use of computers in grade school instruction, with a much weaker effect on teaching methods in middle schools. This is in spite of the fact that program operators hoped to promote the use of CAI at higher grade levels, where it is generally less pervasive. The results reported here do not support the view that CAI improves learning, at least as measured by pupil test scores. Using a variety of estimation strategies, we find a consistently negative relationship between the program-induced use of computers and fourth grade math scores. For other grades and subjects, the estimates are not significant, though also mostly negative. And simpler OLS strategies generate only one significant estimate for the relationship between CAI and test scores, a negative effect of CAI on eighth grade math scores in models with town effects.

A simple explanation for our findings is that CAI is no better and may even be less effective than other teaching methods. As a partial check on this view, we briefly examined a variety of alternative explanations for the insignificant and negative effects reported here. One possibility is that teachers received inadequate training or that non-computer classroom inputs were reduced. Perhaps with more and better

${ }^{6}$ The enormous standard errors for Hebrew fourth grade scores in column 6 are the result of highly correlated residuals within schools in the high-rank sample for that subject/grade category. 
training, or increased resources of other types, CAI results might be better. Our teacher survey included a few questions about variables related to teacher training and the school environment that we use to explore this hypothesis.

Table 7 reports estimates of differences in class size, subject coverage, hours of instruction, teacher training frequency, use of non-computer AV/TV equipment, and teacher satisfaction with training and class size by CAI and Tomorrow-98 program status. The results are for Math scores only. The table shows few differences in the training and school environment variables in either set of contrasts. Its is noteworthy, however, that fourth grade Math teachers in the program group received more frequent training than nonprogram teachers. Another difference for fourth graders is reduced use of non-computer audio-visual equipment (perhaps computers replaced this equipment in the curriculum). Eighth grade Math classes in the program group met less frequently, but the gap is very small.

Another possible explanation for the findings reported here is that the transition to $\mathrm{CAI}$ is disruptive, and the benefits of CAI take time develop. The schools in our sample had Tomorrow-98 computers for an average of one full school year. In future work, we plan to explore longer-term impacts with more recent data, collected in 1997. It should be noted, however, that our results show that enough time had passed by the test date for the new computers to have had a significant impact on instructional methods for fourth graders. Moreover, the costs of additional CAI did not take very long to appear. As noted in the introduction, the Tomorrow-98 program deployed about 35,000 computers in the first three years of the program. The Ministry of Education budgets this deployment at $\$ 3,000$ per machine, include the cost of hardware, software, and set-up (but not including wiring or other physical infrastructure). Program schools received an average of about 40 computers, for a cost of $\$ 120,000$ per school. In Israel, this amount would pay the wages of 4 full-time teachers. Assuming a depreciation rate of $25 \%$ on hardware and software and ignoring any training costs, the flow cost of the computers is about one teacher per year per school. The question of future impacts remains open, but this significant and ongoing expenditure does not appear to be justified by pupil performance results to date. 


\section{DATA APPENDIX}

\section{A. Test score data}

Four data files from the Ministry of Education contain the pupil's characteristics and test scores (in Math and Hebrew, for 4th and 8th grade) from the June 1996 national testing program. These files were given to us by the Ministry of Education. Our analysis is limited to the Jewish schools in the sample. The 4th grade Math sample included 213 schools (5584 pupils). The 8th grade Math sample included 177 schools (4172 pupils). The 4th grade Hebrew sample included 209 schools (5466 pupils). The 8th grade Hebrew sample included 176 schools (4695 pupils).

\section{B. Computer-use intensity data}

The June 1996 testing program included a brief survey given to all teachers of each sampled class. This survey included a question on the intensity of computer use in the classroom. Teachers are identified as Math or Hebrew teachers. Fourth grade pupils were assigned the answers of their (unique) teacher. For the 8th Hebrew sample, there are up to four different teachers who thought the same class different Hebrew-related subjects. In such cases we assigned pupils the answers of their reading teacher.

Teachers' answers on the intensity of computer use were non-missing for 183 schools ( 4833 pupils) in the 4th grade Math sample, 142 (3290 pupils) schools in the 8th grade Math sample, 166 schools (4180 pupils) in the 4th grade Hebrew sample and for 140 schools ( 3675 pupils) in the 8 th grade Hebrew sample. The observation counts were further reduced to those in Table 1 because of missing data on other variables.

\section{Data on Tomorrow-98 applicants}

The Ministry of Education provided a file containing information on the 1994 applicants to the Tomorrow-98 program and their ranking within municipalities. This file was merged with pupil test scores data using the school id. The 4th and 8th grade applicant Math samples with test score data included 146 schools. The 4th and 8th grade applicant Hebrew samples with test score data included 144 and 140 schools, respectively.

The Ministry of Education also provided files with information on the Tomorrow implementation schedules and existing computer infrastructure (collected for the purposes of this evaluation), along with other school level variables, such as the Pupil Disadvantage index, school size, town code and type of school (secular or religious). We were able to match all of the pupils in the table above to this school-level data.

\section{Lagged test score and computer use data}

Lagged scores for 4th grade Math and Hebrew scores were obtained from the 1991 national test program data used by Angrist and Lavy (1991). Lagged scores were available for 189 schools in the 4th grade Math sample (of which 131 were program applicants), for 130 schools in the 8th grade Math sample (110 program applicants), for 188 schools in the 4th grade Hebrew sample (150 program applicants) and for 119 schools in the 8 th grade Hebrew sample (97 program applicants). The estimates controlling for lagged computer use in Table 5 also rely on matched data for a subsample of schools from the 1991 testing program. The data come from a survey of teachers that was done along with the 1991 testing. The lagged use variable in our analyses measures the proportion of teachers at each school in 4th grade using computers for instruction in 1991. The 8th grade lagged use variable is the average lagged use dummy for 4th grade in elementary schools that feed the relevant middle schools. 


\section{REFERENCES}

Anandakrishan, M., J.F. Cardenas, P. Galaz-Fontes, and P. Robles-Perez, "Microcomputers in Schools in Developing Countries," pp. 112-126 in New Technologies and Development: Experiences of Technology Blending, A.S. Bhalla and J. Dilmus, eds., London: Rienner, 1988.

Cuban, L. Teachers and Machines: The Classroom Use of Technology Since 1920, New York: Teacher's College Press, 1986.

Angrist, J., and G. Imbens, "Two-Stage Least Squares Estimates of Average Causal Response in Models with Variable Treatment Intensity," Journal of the American Statistical Association, June 1995.

Angrist, J., and V. Lavy, "Using Maimonides' Rule to Estimate the Effect of Class Size on Student Achievement," Quarterly Journal of Economics, May 1999.

Baker, Eva L., M. Gearhart, and J.L. Herman, "The Apple Classrooms of Tomorrow: The UCLA Evaluation Studies, CSE technical report 353, Center for the Study of Evaluation/Center for Technology Assessment, Graduate School of Education, UCLA, January 1993.

Booms, B.H., and D.L. Kaltreider, "Computer-Aided Instruction for Large Elementary Courses," American Economic Review 64 (May 1974), 408-413.

Cleveland, W., "Robust Locally Weighted Regression and Smoothing Scatterplots," Journal of the American Statistical Association 74 (1979), 829-836.

Cuban, L., Teachers and Machines: the Classroom Use of Technology Since 1920, New York: Teacher's College Press, 1986.

Cuban, L., "Computers Meet Classroom: Classroom Wins," Teacher's College Record 95 (1993), 185-210.

Dertouzos, Michael, "Wire All Schools? Not So Fast ...," Technology Review (September-October 1998), 20.

Fan, J., and I. Gijbels, Local Polynomial Modeling and Its Applications, London: Chapman and Hall, 1995.

Hahn, Jinyong, P. Todd, and Wilbert van der Klaauw, "Evaluating the Effect of an Anti-discrimination Law Using a Regression-Discontinuity Design," NBER Technical Working Paper No. 7131, May 1999.

Henry, Mark, and D. Ramsett, "The Effects of Computer-Aided Instruction on Learning and Attitudes in Economic Principles Courses," Journal of Economic Education 10 (Fall 1978), 26-34.

Israel, Paul, Edison: A Life of Invention, New York: John Wiley and Sons, 1998 (p. 442).

Israel Ministry of Education, Culture, and Sport, Economics and Budgeting Administration, Facts and Figures About Education and Culture in Israel, Jerusalem: 1994.

Israel Ministry of Education, Culture, and Sport, Economics and Budgeting Administration, Facts and Figures About Education and Culture in Israel, Jerusalem: 1996.

Kirkpatrick, Heather, and L. Cuban, "Computers Make Kids Smarter -- Right?," Technos Quarterly for Education and Technology 7 (Summer 1998), No. 2.

Knight, Patricia Burns, and W.C. Bozeman, "Computer-Assisted Instruction and Mathematics Achievement: Is There a Relationship?," Educational Technology (October 1981), 32-39.

Krueger, Alan, "How Computers Have Changed the Wage Structure," Quarterly Journal of Economics 108 (February 1993).

Kulik, C.C., and J.A. Kulik, "Effectiveness of Computer-Based Instruction: An Updated Analysis," Computers in Human Behavior 7 (1991), 75-94.

Lavy, Victor, "Endogenous School Resources and Cognitive Achievement in Primary Schools in Israel," Hebrew University, Falk Institute Discussion Paper No. 95.03, 1995.

Levy, Frank, and Richard Murnane, "With What Skills are Computers a Complement?," American Economic Review (May 1998), 258-262.

Lewis, Darrell R., James C. Hearn, and Eric Zilbert, "Keyboarding as General Education: Post-School Employment and Earnings Effects," Economics of Education Review 10 (1991), 333-342.

Liao, Y.K., "Effects of Computer-Assisted Instruction on Cognitive Outcomes: A Meta-Analysis," Journal of Research on Computing in Education 24 (1992), 367-380. 
Moulton, Brent, "Random Group Effects and the Precision of Regression Estimates," Joumal of Econometrics 32 (1986), pp. 385-97.

Oppenheimer, Todd, "The Computer Delusion," The Atlantic Monthly (July 1997), 45-63.

President's Committee of Advisors on Science and Technology, Panel on Educational Technology, Report to the President on the Use of Technology to Strengthen K-12 Education in the United States," Washington DC: Office of the President, March 1997.

Seltz, Johanna, 'Some Educators Question Value of School Computers," The Boston Sunday Globe (May 9, 1999), p. F5.

Skinner, B.F., "The Science of Learning and the Art of Teaching," Harvard Educational Review 24 (1954), $86-97$.

Skinner, B.F., "Teaching Machines," Science 128 (October 24, 1958), 969-977.

Stoll, Clifford, Silicon Snake Oil: Second Thoughts on the Information Highway, New York: Doubleday, 1995.

Wenglinsky, Harold, Does It Compute? The Relationship Between Educational Technology and Student Achievement in Mathematics, Policy Information Center, Research Division, Educational Testing Service, Princeton, NJ: September 1998. 


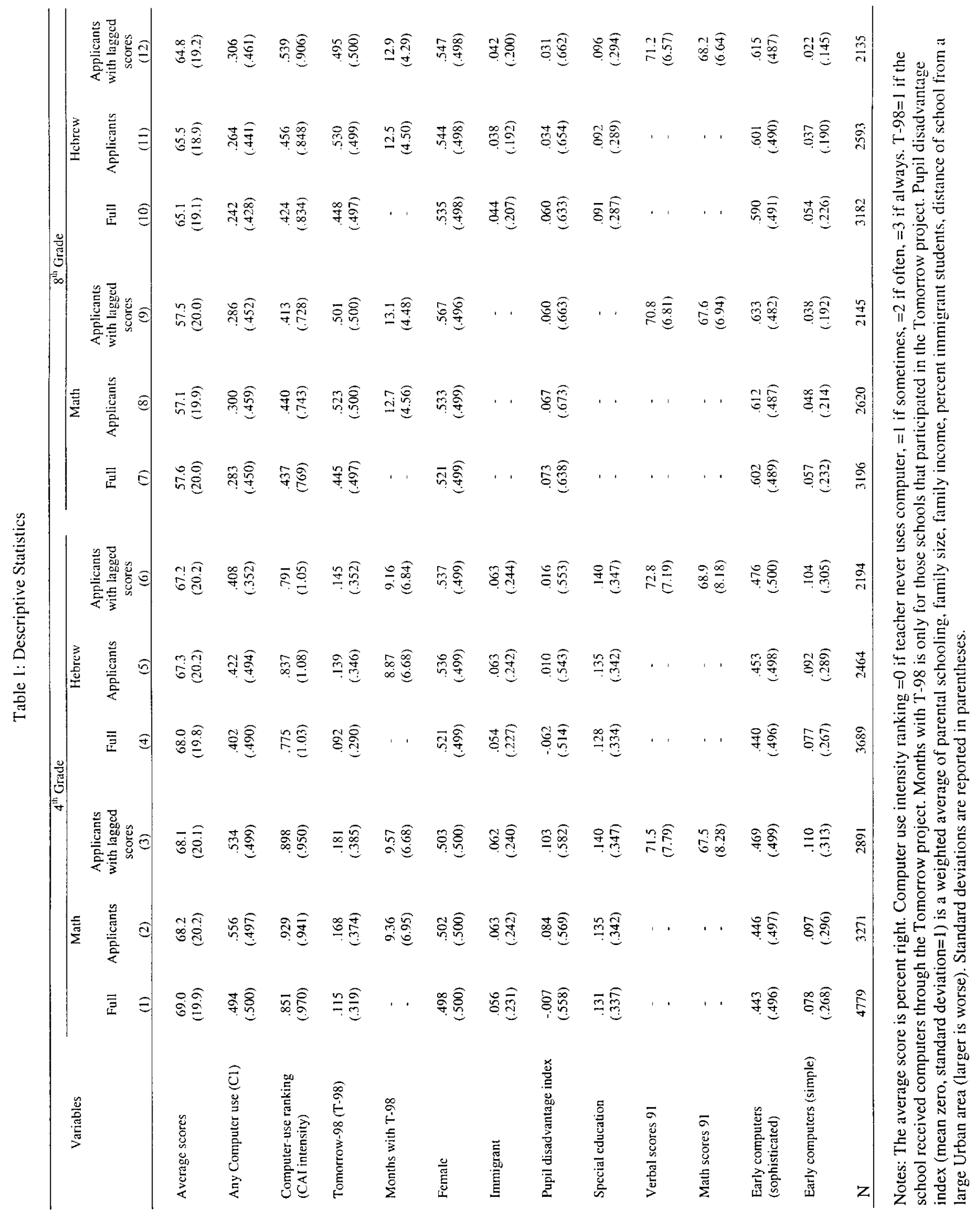




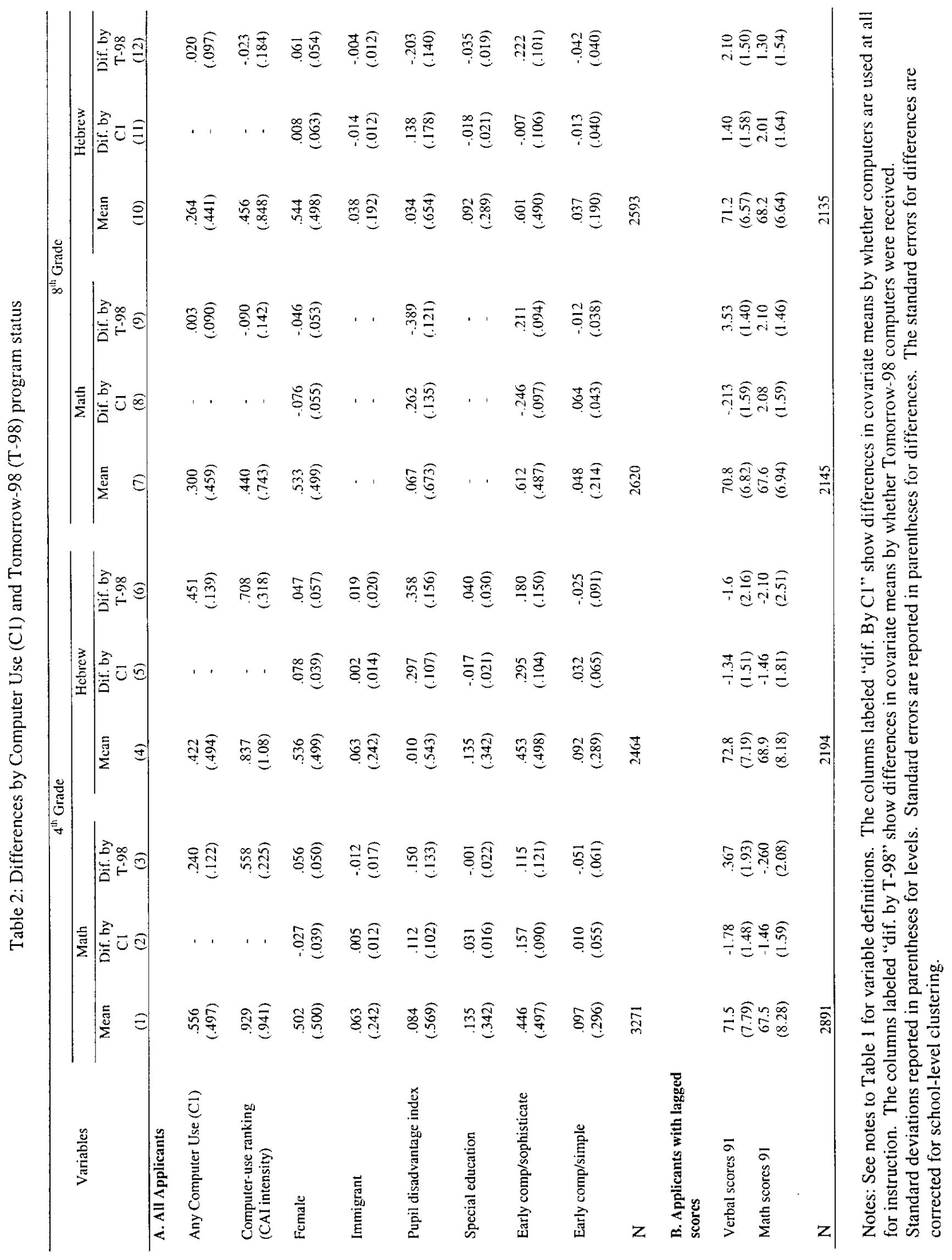




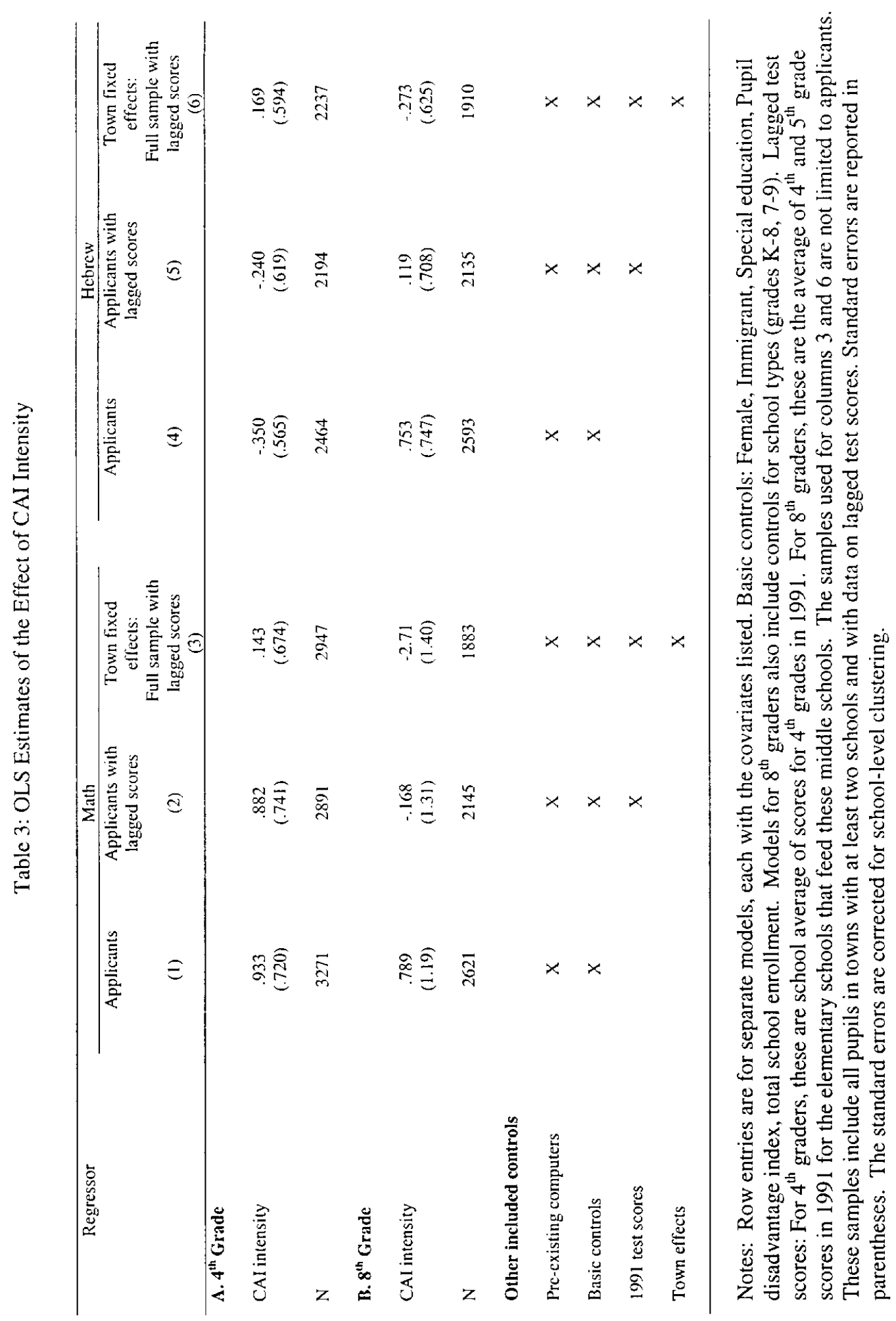




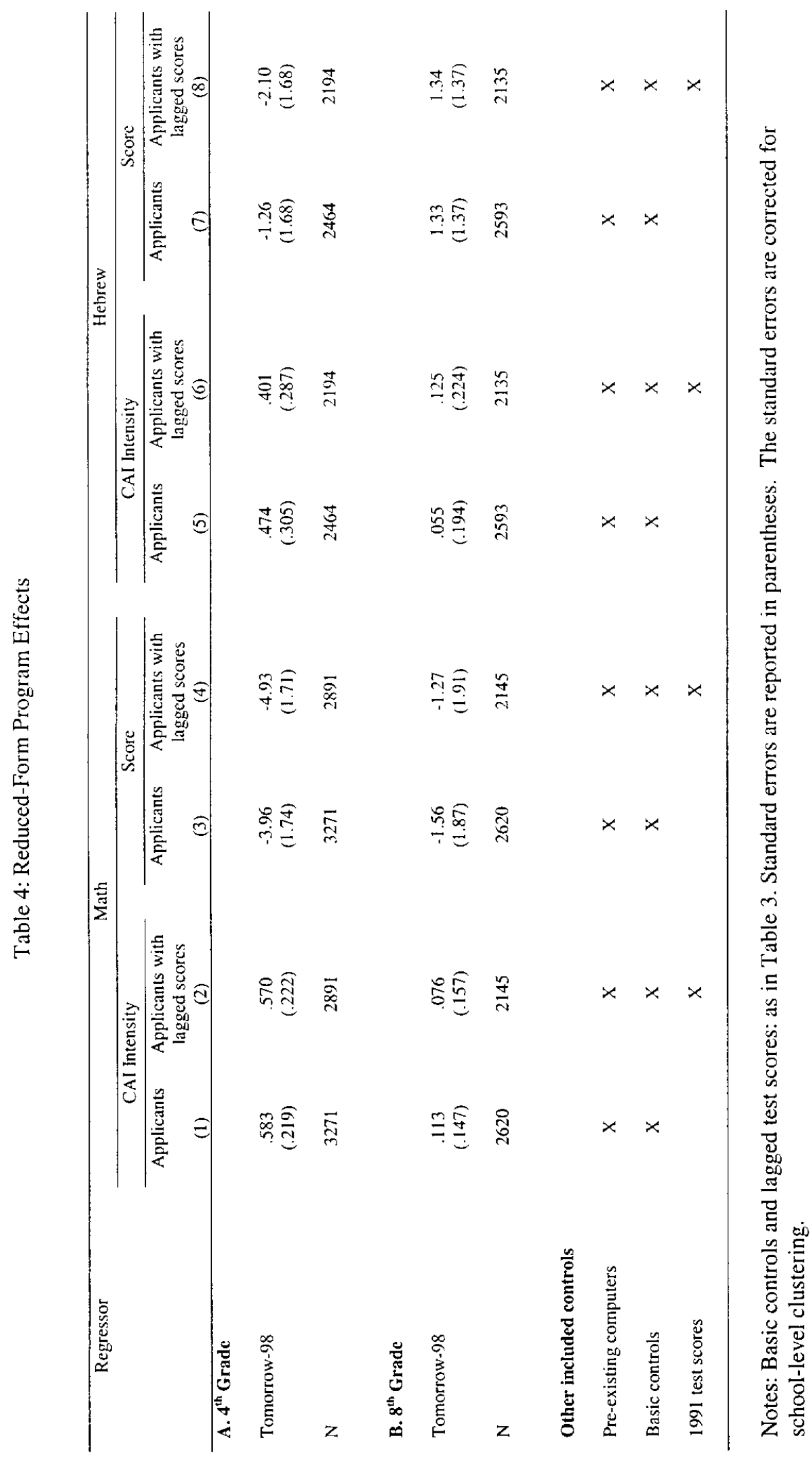




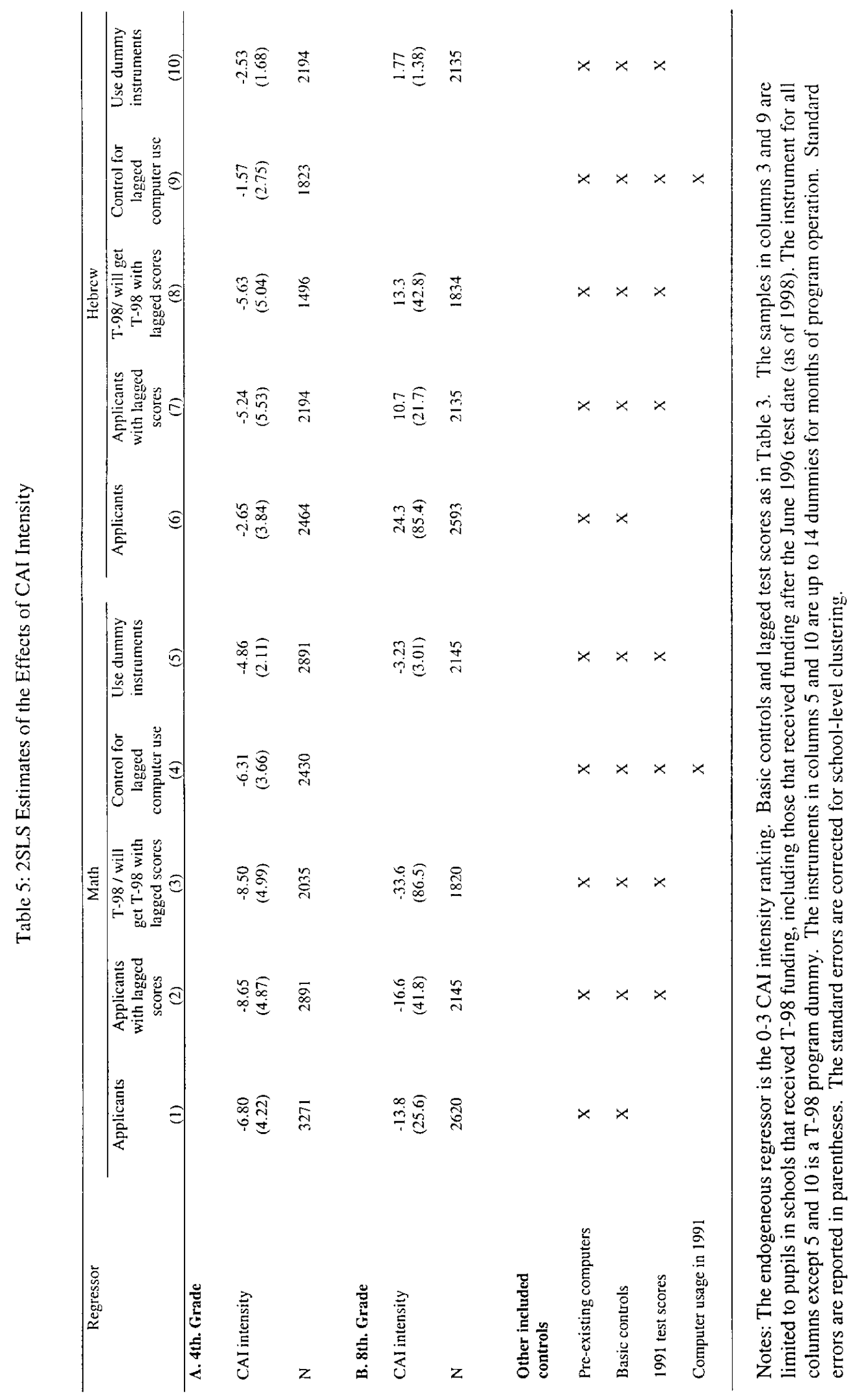




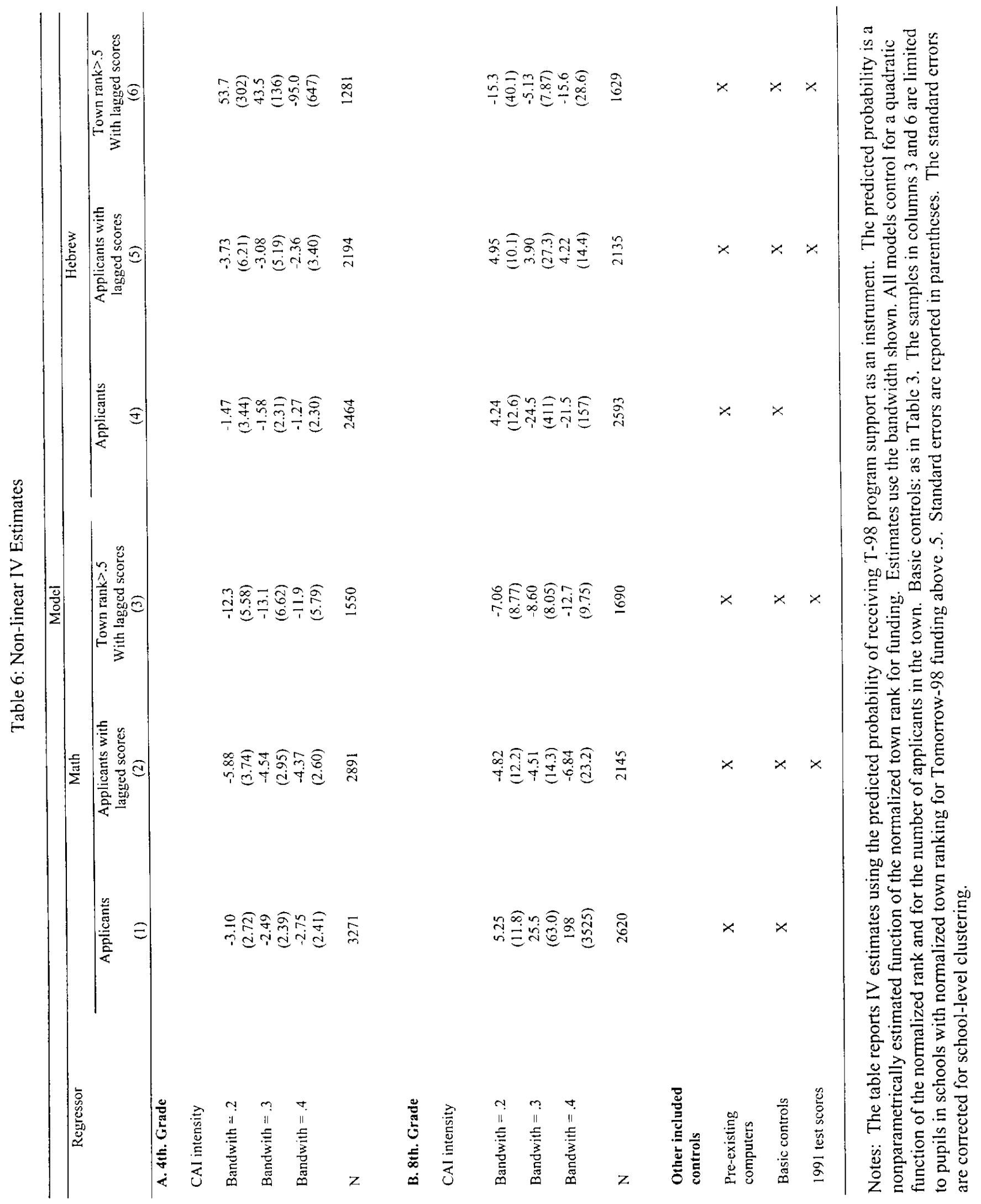




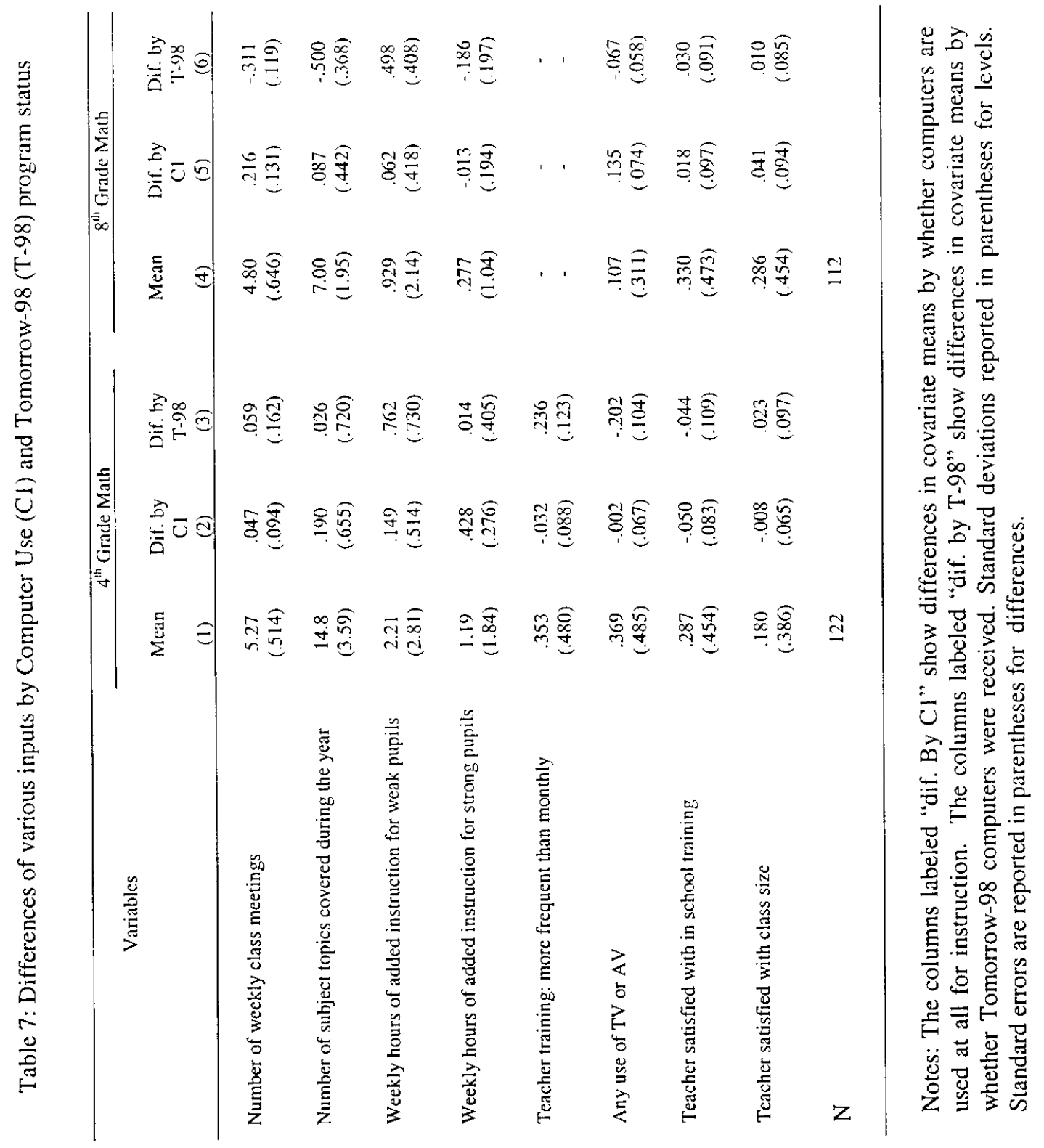


Lowess smoother, bandwidth $=.2$

Elementary Schools

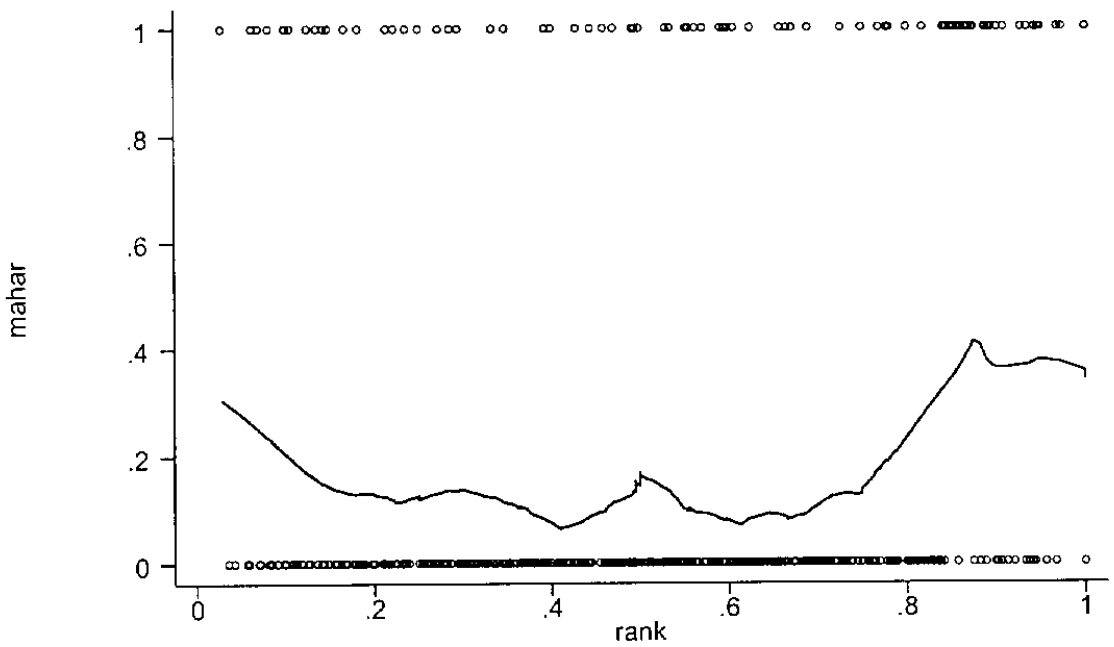

Lowess smoother, bandwidth $=.3$

Elementary Schools
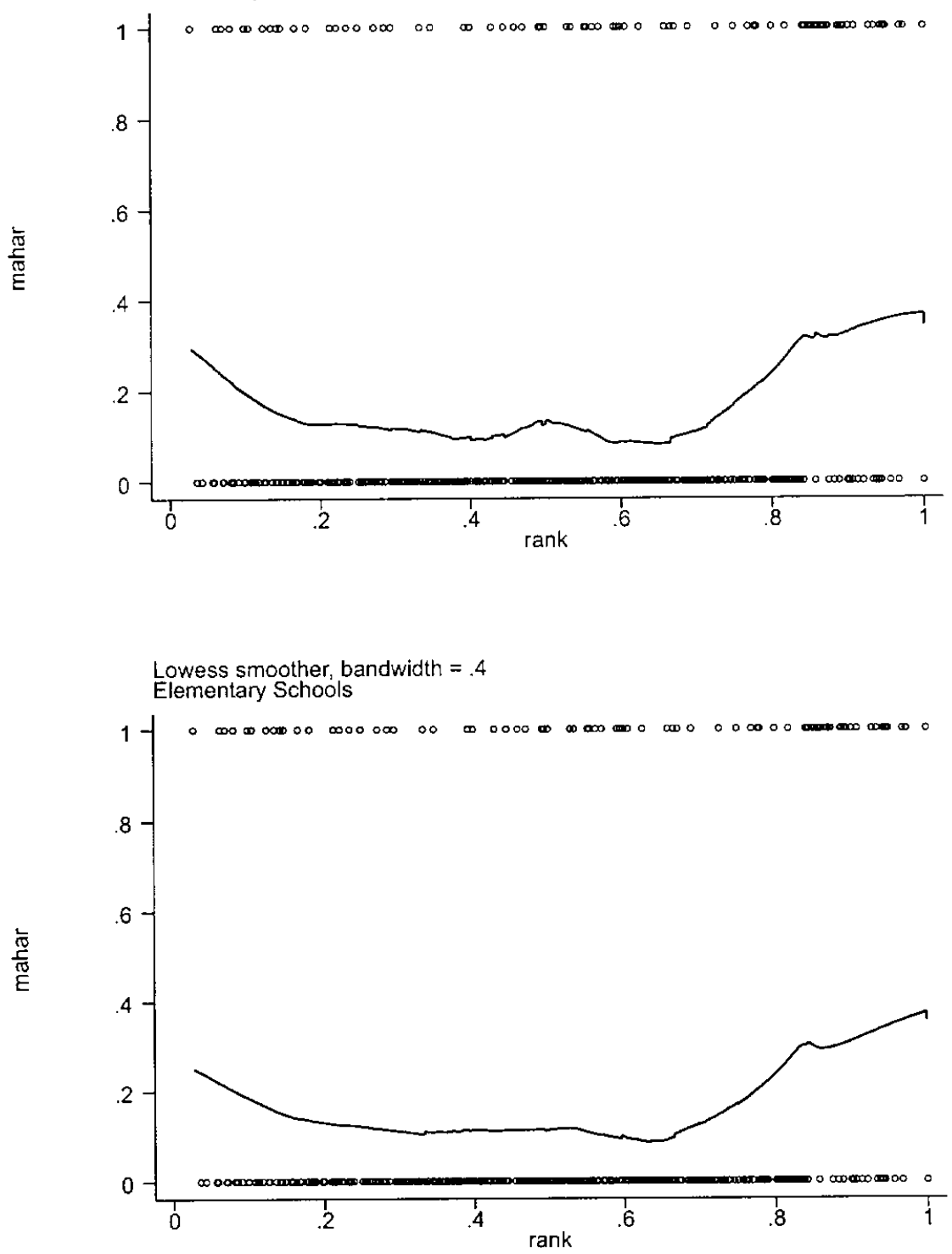

Figure 1. The relationship between within-town rank and the probability of funding for elementary schools. 
Lowess smoother, bandwidth $=.2$ Middle Schools

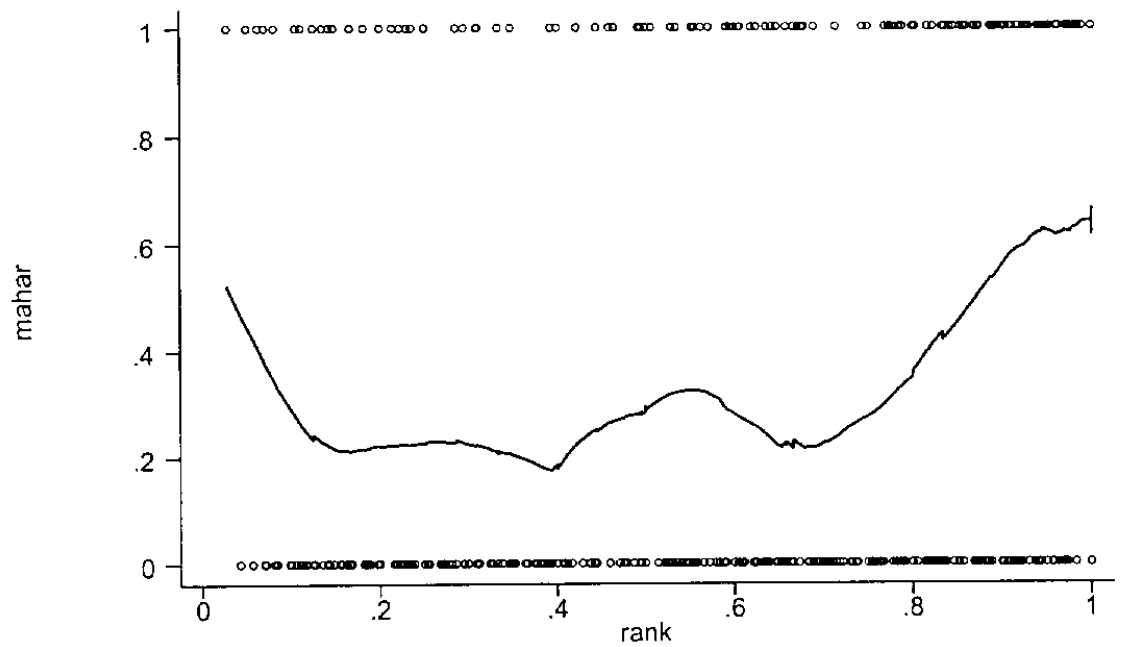

Lowess smoother, bandwidth $=.3$ Middle Schools

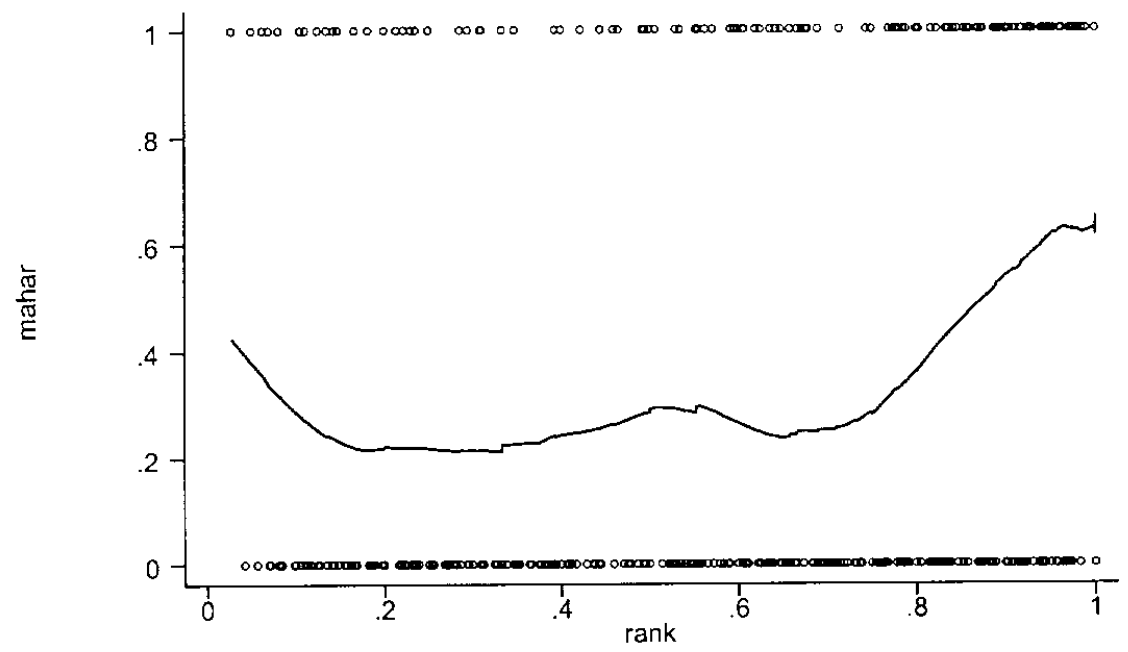

Lowess smoother, bandwidth $=.4$ Middle Schools

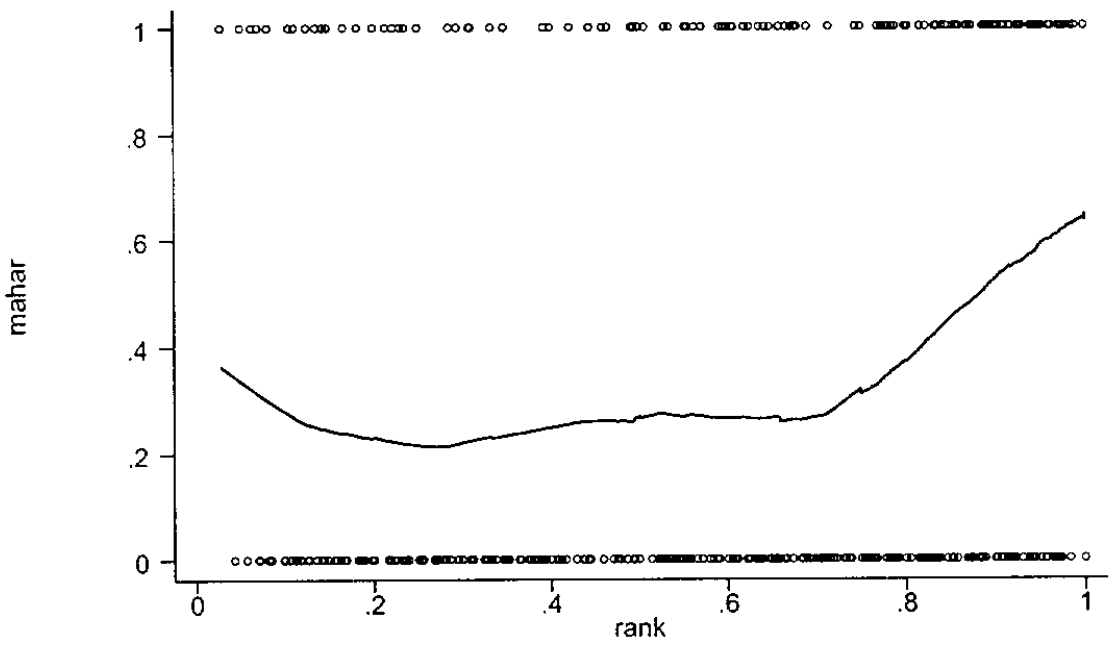

Figure 2. The relationship between within-town rank and the probability of funding for middle schools. 


\section{Math}

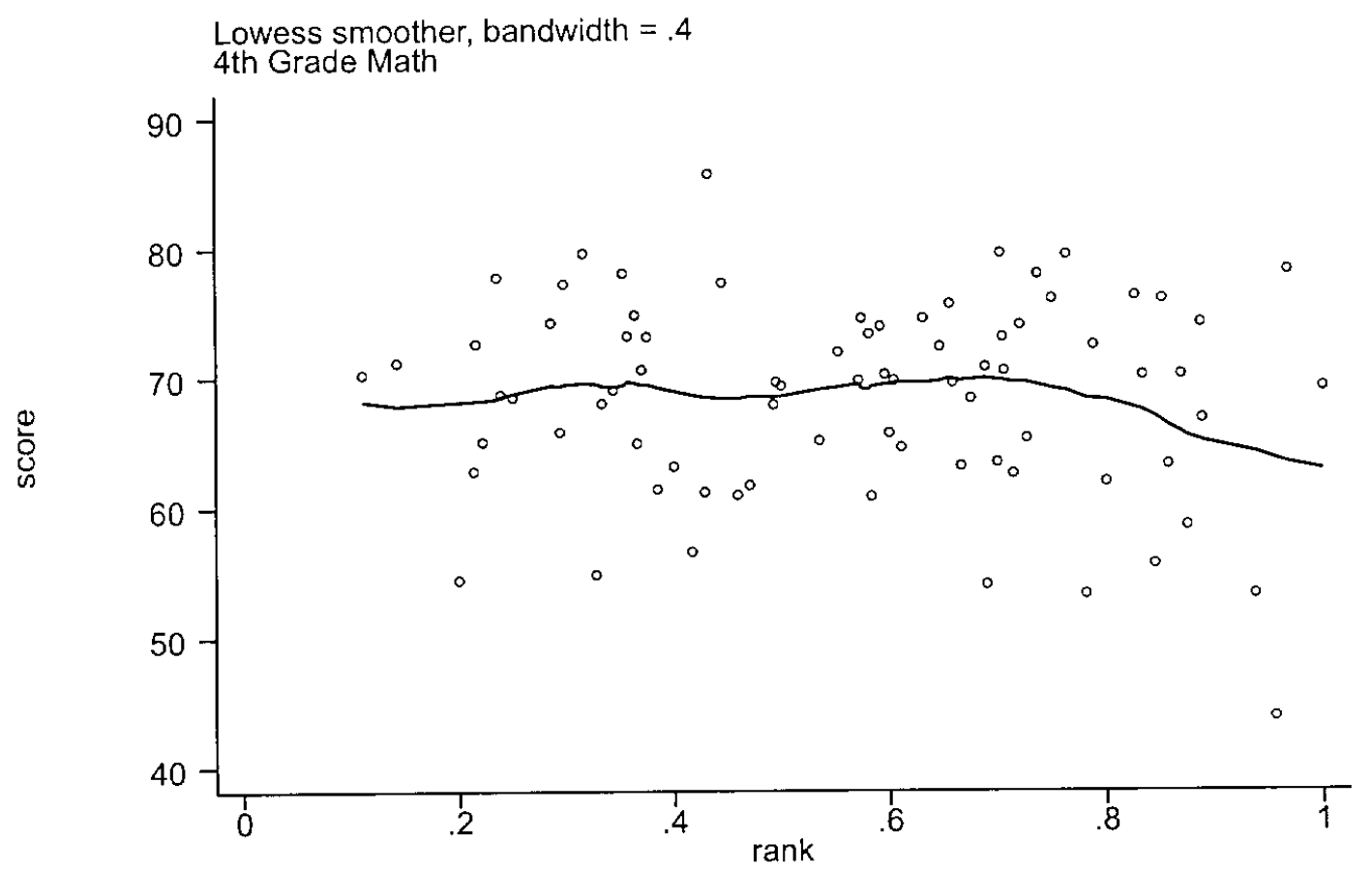

\section{Verbal}

Lowess smoother, bandwidth $=.4$

4th Grade Hebrew

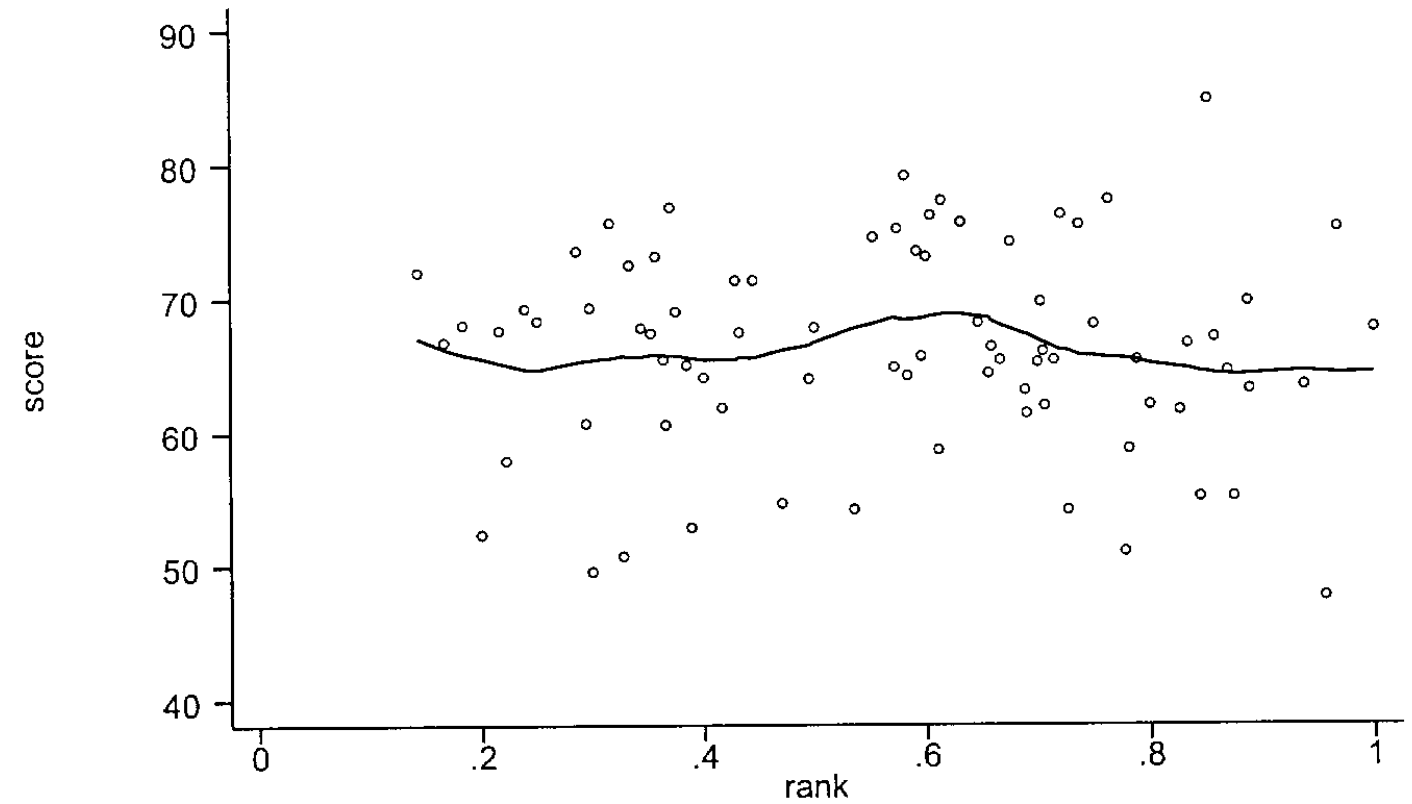

Figure 3. The relationship between within-town rank and test scores for 4 th grade. 


\section{Math}

Lowess smoother, bandwidth $=.4$

8th Grade Math

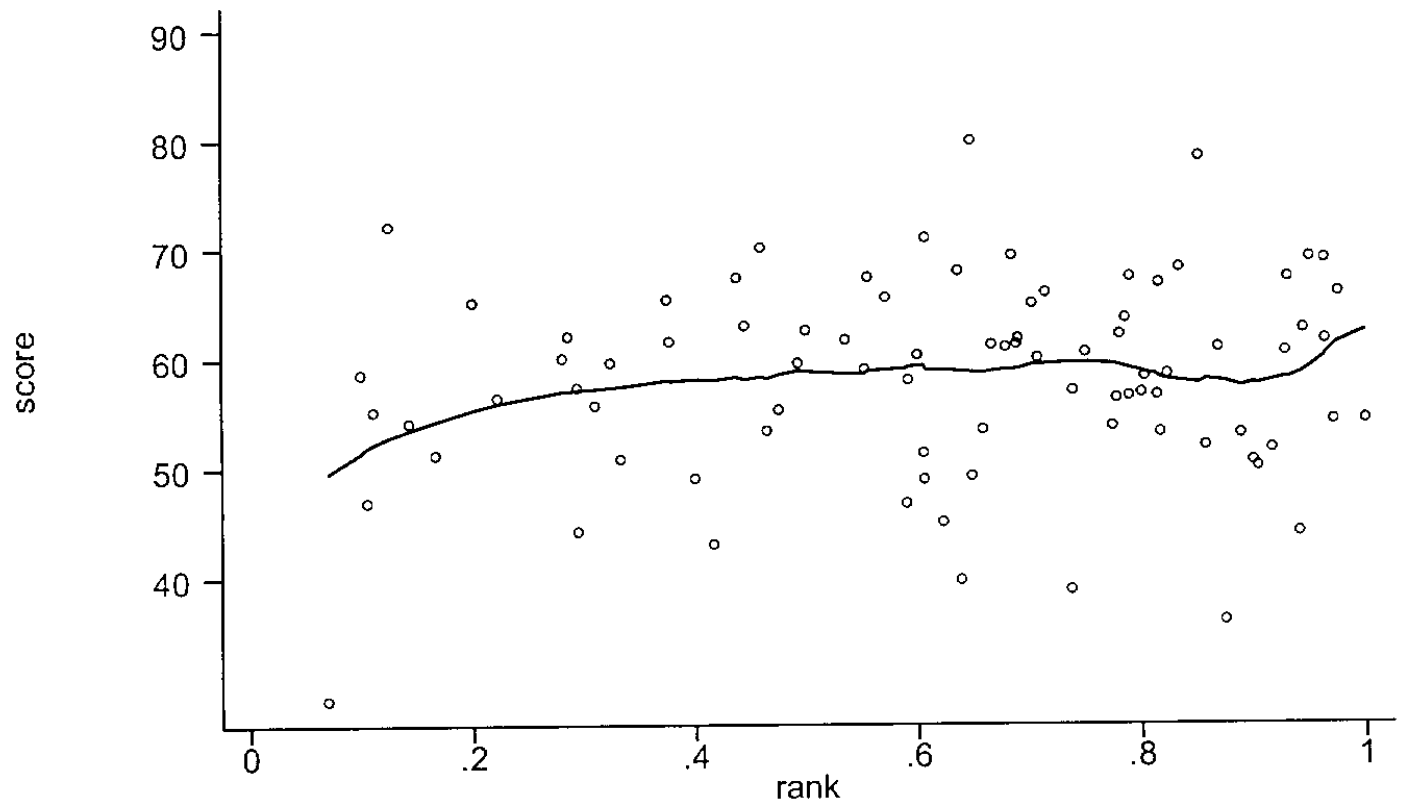

Verbal

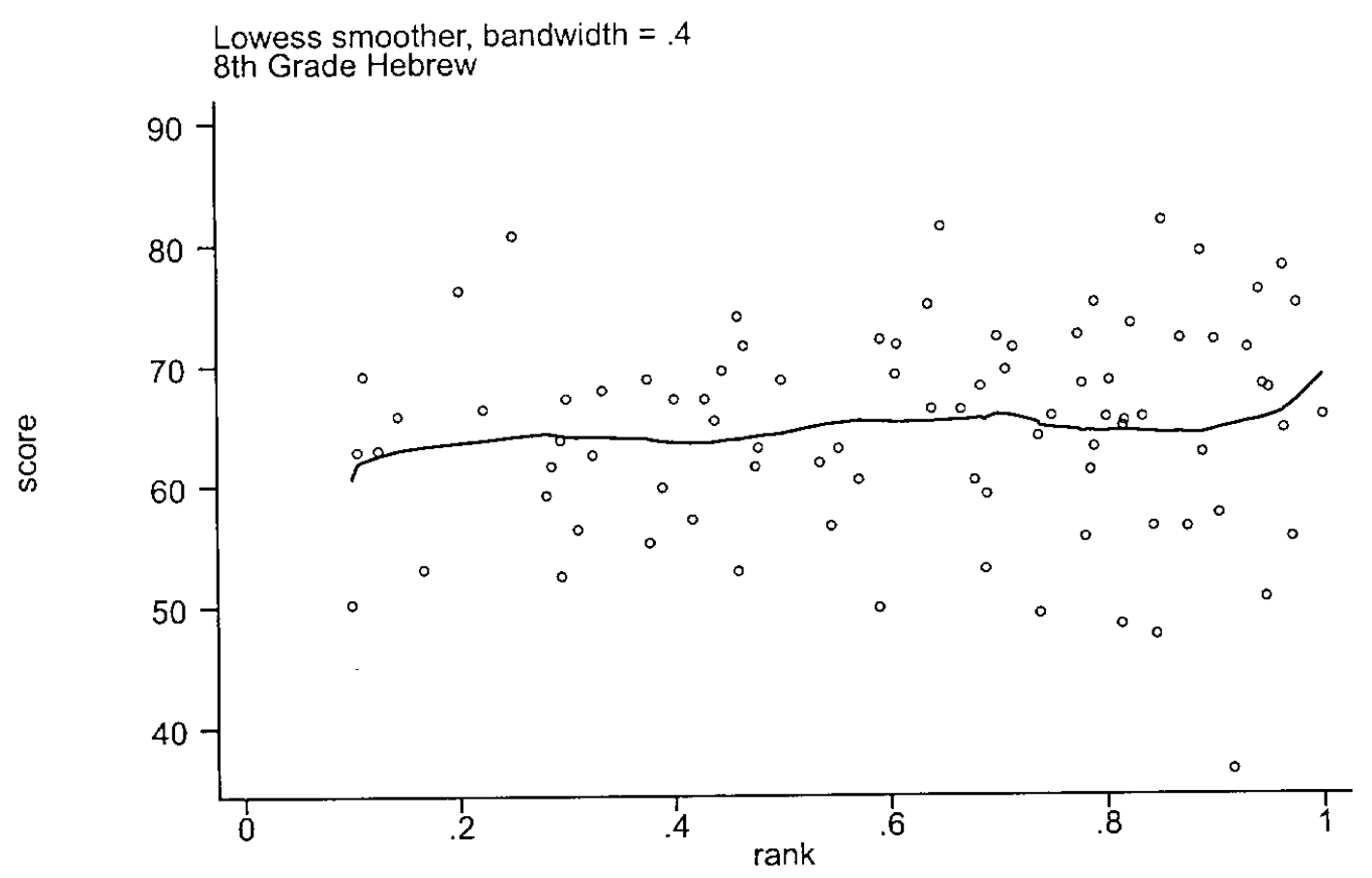

Figure 4 . The relationship between within-town rank and test scores for 8 th grade. 